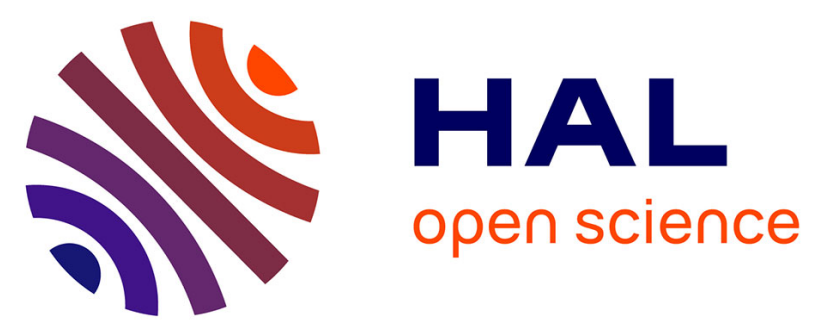

\title{
Living with predators at the larval stage has differential long-lasting effects on adult life history and physiological traits in two anopheline mosquito species
}

Olivier Roux, D Renault, Karine Mouline, Abdoulaye Diabaté, Frédéric Simard

\section{To cite this version:}

Olivier Roux, D Renault, Karine Mouline, Abdoulaye Diabaté, Frédéric Simard. Living with predators at the larval stage has differential long-lasting effects on adult life history and physiological traits in two anopheline mosquito species. Journal of Insect Physiology, 2021, 131, pp.104234. 10.1016/j.jinsphys.2021.104234 . hal-03222789

\section{HAL Id: hal-03222789 \\ https://hal.science/hal-03222789}

Submitted on 11 Jun 2021

HAL is a multi-disciplinary open access archive for the deposit and dissemination of scientific research documents, whether they are published or not. The documents may come from teaching and research institutions in France or abroad, or from public or private research centers.
L'archive ouverte pluridisciplinaire HAL, est destinée au dépôt et à la diffusion de documents scientifiques de niveau recherche, publiés ou non, émanant des établissements d'enseignement et de recherche français ou étrangers, des laboratoires publics ou privés. 
1 Living with predators at the larval stage has differential long-lasting effects on adult life

2 history and physiological traits in two anopheline mosquito species

3

4 Olivier Roux ${ }^{1,2^{*}}$, David Renault ${ }^{3,4}$, Karine Mouline ${ }^{1,2}$, Abdoulaye Diabaté ${ }^{2}$ and Frederic

5 Simard $^{1}$

6

7 1. MIVEGEC, IRD, CNRS, Univ. Montpellier, Montpellier, France.

8

2. Institut de Recherche des Sciences de la Santé (IRSS), Bobo-Dioulasso, Burkina Faso.

3. Univ Rennes, CNRS, ECOBIO [(Ecosystèmes, biodiversité, évolution)] - UMR 6553, F35000 Rennes, France

4. Institut Universitaire de France, 1 Rue Descartes, 75231 Paris cedex 05, France

Key words: Anopheles gambiae, Anopheles coluzzii, Carry-over effect, Life history traits,

Malaria vectors, Oxidative stress, Predation stress, Teneral reserves. 


\section{Abstract:}

1. Under predation stress, individuals increase their metabolic rate and adopt different resource allocation strategies to favor their direct survival to the detriment of growth, reproduction and self-maintenance. Species and sexes are both faced with different physiological and life history demands and should adopt different strategies which lead to carry-over effects on adult metabolic reserves and on oxidative status.

2. Malaria mosquitoes Anopheles coluzzii and An. gambiae are sibling species. In nature, their larvae are exposed to different levels of predation risk and An. coluzzii larvae are more capable of surviving predation threats than An. gambiae, because of a better ability to gauge the threat level and to produce an adapted behavioral response. Impact of this response on adult physiology is however unknown.

3. Here, we investigated the carry-over effects of larval predation stress: first, on life history traits such as development length, size and weight at emergence, fecundity and survival; second, on metabolic resources at emergence such as lipids, proteins, carbohydrates and amino acids; and third, on oxidative status with the total anti-oxidant capacity and the oxidation of proteins in the two species and in both sexes.

4. We found that on one hand, it took more time for An. coluzzii to develop in presence of a predator and they emerged with a smaller size but a similar weight as control individuals. On the other hand, An. gambiae exposed to predators developed as fast as controls but with both a smaller size and a smaller weight. Fecundity was negatively impacted in both species following exposure to predation threats. Teneral reserves were affected depending on the species and the sex. The total anti-oxidant capacity of individuals exposed to stress was lower than in the controls but a significant level of damages to proteins was detected in An. gambiae males only. 
5. Our findings suggest that predation stress induces very different physiological responses even in closely related species and between sexes. Allocation of resources in larvae may differ and depend on the species' aptitude to develop in presence of predators and on the sex, since males and females might adopt different strategies to fulfill their fitness. 


\section{Introduction}

Non-consumptive predation effects are significant drivers of the behavioral, physiological, morphological and life history traits of individuals (Lima, 1998; Benard, 2004; Preisser, Bolnick \& Benard, 2005; McCauley, Rowe \& Fortin, 2011). Under predation risk, prey often exhibit reduced foraging activities, which lowers nutrient acquisition in addition to shifting resource allocation from growth, reproduction and self-maintenance to direct survivorship (Lima \& Dill, 1990). This symptomatic response is thus accompanied by a reduction in protein content to the benefit of carbohydrates (McPeek, Grace \& Richardson, 2001; Stoks, De Block \& McPeek, 2005). In parallel, the vigilance of the prey is heightened, and its metabolic rate increases (i.e. respiration) to fuel emergency functions more rapidly (General Stress Paradigm, Hawlena \& Schmitz, 2010).

Predator-induced phenotypic changes can be especially pervasive during development, with strong carry-over effects on adult phenotypes (Benard \& Fordyce, 2003; De Block \& Stoks, 2005; Pechenik, 2006; Crean, Monro \& Marshall, 2011; McCauley et al., 2011). These latent effects can be mediated either by the decreased foraging activity of prey which make them less conspicuous (Lima \& Dill, 1990; Ferrari, Messier \& Chivers, 2008; Roux, Diabate \& Simard, 2013), by the exploitation of patches of resources that are less time-consuming for the individual but which may also be of lower quality, or by physiological adaptations that may alter the way nutrients are assimilated and allocated to growth or emergency needs (Slos \& Stoks, 2008; Van Dievel, Janssens \& Stoks, 2016). In insects, the decreased quality and quantity of food intakes and the overconsumption of energetic metabolites such as lipids and carbohydrates lower the amount of body stores (McPeek et al., 2001; Stoks et al., 2005; Hawlena \& Schmitz, 2010). This has significant consequences for the individuals, since body reserves can be depleted after larvae achieve the energetically demanding metamorphosis stage (Pechenik, 2006 and references therein), with dramatic consequences for the subsequent 
fitness of the adult (Boggs, 1981; Briegel, 1990; Telfer \& Kunkel, 1991; Telang, Buck \& Wheeler, 2002).

Moreover, while enhancing chances to survive and escape predator attacks, the antipredator responses affect energy budgets by shunting energy away from several other physiological functions, including antioxidant activities (Stoks et al., 2005; Selman, Blount, Nussey \& Speakman, 2012; Janssens \& Stoks, 2013; Costantini, 2014). Recently, it has been shown that predation stress is a source of oxidative stress (Janssens \& Stoks, 2013) and affects enzymatic kinetics (Slos \& Stoks, 2008; Guerra, Zenteno-Savín, Maeda-Martínez, Abele \& Philipp, 2013; Pinya, Tejada, Capó \& Sureda, 2016), life history traits such as longevity, fecundity and motility (Travers, Clinchy, Zanette, Boonstra \& Williams, 2010; Janssens \& Stoks, 2014) and their trade-offs (Dowling \& Simmons, 2009; Monaghan, Metcalfe \& Torres, 2009; Metcalfe \& Alonso-Alvarez, 2010; Selman et al., 2012; Costantini, 2014). Yet, response to oxidative stress is highly variable between species, and it has often been challenging to draw consistent conclusions within ecological and evolutionary frameworks so far. In this context, investigations based on recently diverged incipient species can provide new insights into understanding inter- and intra- specific differences in antioxidant responses and their potential impact in promoting divergences in life history traits (Costantini, 2008).

The Anopheles gambiae complex (African malaria mosquitoes) is particularly well suited to investigations on the evolution of anti-predator responses and carry-over effects on adult life histories. Indeed, in sub-Saharan Africa, Anopheles gambiae s.s. and An. coluzzii, two cryptic species of this complex, are exposed to different predation pressures at the larval stage (Diabaté et al., 2008). In western Burkina Faso, although the adults are found in sympatry, larvae might thrive in different habitats. Anopheles coluzzii is dominant in permanent freshwater habitats (e.g. irrigated fields such as rice paddies), which shelter higher 
densities of predators than temporary water habitats (e.g. puddles, quarries, ruts) where $A n$. gambiae predominates (Sunahara, Ishizaka \& Mogi, 2002; Diabaté et al., 2008; Gimonneau et al., 2012a). Furthermore, An. coluzzii larvae are known to be better at gauging the level of predation risk and are more capable of triggering anti-predator response compared to $A n$. gambiae larvae (Diabaté et al., 2008; Gimonneau et al., 2010; Roux et al., 2013; Roux, Diabate \& Simard, 2014).

So far, no studies have explored the effect of predation risk on sibling species and in both sexes, despite the fact that it can have significant consequences on life history traits for these anopheline insects and potential malaria epidemiological outcomes (Roux et al., 2015). This study was thus aimed at investigating the carry-over effects of a chronic larval predation stress on adults of the sibling species An. gambiae and An. coluzzii by measuring traits describing fecundity, size and longevity, in addition to the characterization of a range of physiological parameters (antioxidant capacities, nature and amount of metabolic reserves) in both males and females. We expected that i) predation risk would reduce nutrient acquisition and transformation at the larval stages, leading to smaller adult sizes; ii) larvae would maximize the use of lipids and carbohydrates (fight-or-flight response) at the detriment of protein and amino acid stores (Stoks et al., 2005; Hawlena \& Schmitz, 2010; Van Dievel et al., 2016), thus modifying the body reserves of teneral insects; iii) these altered teneral reserves would induce a significant reduction of female fecundity (Uchida et al., 2001; Zhou, Pennington \& Wells, 2004); and iv) larvae that grew under predation risk would have suffered from a higher production of oxidative molecules with long-lasting footprints on adults (i.e. enhanced antioxidant capacities in the adults and/or increased oxidative damages to proteins).

\section{Material and Methods}

\section{Insect collections}


Experiments were conducted with F1 to F3 mosquito larvae obtained from wild $A n$. gambiae s.l. females collected while at rest in inhabited human dwellings in villages from south-western Burkina Faso (West Africa). An. coluzzii specimens were collected in Bama $\left(11^{\circ} 23^{\prime} 14^{\prime \prime} \mathrm{N}, 4^{\circ} 24^{\prime} 42^{\prime \prime} \mathrm{W}\right)$, a village surrounded by irrigated rice fields in which females lay their eggs and where the predation density is known to be high (permanent water reservoirs). An. gambiae were collected in Soumousso $\left(11^{\circ} 00^{\prime} 46^{\prime \prime} \mathrm{N}, 4^{\circ} 02^{\prime} 45^{\prime \prime} \mathrm{W}\right)$, a village in humid savanna where females only have access to temporary, rain-filled puddles and quarries, and where predator density is low. After individual oviposition, females were identified to the species' level by routine PCR-RFLP (Santolamazza et al., 2008). The larvae were reared in spring water under insectary conditions $\left(27 \pm 1^{\circ} \mathrm{C}, 80 \pm 10 \%\right.$ relative humidity, $\left.12 \mathrm{~L}: 12 \mathrm{D}\right)$ and fed with Tetramin ${ }^{\circledR}$ Baby Fish Food ad libitum. Adults were reared in mesh cages $(30 \times 30 \times 30 \mathrm{~cm})$ and provided with $5 \%$ glucose and water on imbibed cotton wool pads ad libitum.

Backswimmer Anisops jaczewskii (Hemiptera: Notonectidae) is the most abundant and widespread predatory bug in mosquito larval habitats in our study area (Diabaté et al., 2008). Predators were collected from both mosquito sampling villages. They were fed daily $a d$ libitum with both An. gambiae and An. coluzzii larvae and maintained in the same controlled insectary conditions as the mosquito larvae. All the predators used in the experiment were adults of similar sizes.

\section{Experimental design}

Exposure to predator - 300 first instar larvae and one predator were placed together in a plastic container (Lxwxh: 28x18x5.5cm) filled with $1 \mathrm{~L}$ of spring water under insectary conditions. The predator was free to feed upon mosquito larvae during the entire period of larval mosquito development. To standardize hunger levels, predators were starved for $48 \mathrm{~h}$ 
and then fed with 20 third instar mosquito larvae $12 \mathrm{~h}$ before the beginning of the experiment. Indeed, fully starved predators were not adequate because they ate all the first instar larvae within the first $48 \mathrm{~h}$ of exposure at the beginning of the experiment. For each experimental container, its equivalent without a predator was set up as a control. Twenty-four containers were setup, 10 containers for An. coluzzii ( 5 experimental and 5 controls) and 14 containers for An. gambiae (7 experimental and 7 controls) (Fig. 1). The presence of a predator and chemical cues associated with killing and consumption of mosquito larvae have been shown to induce anti-predator behaviors in Anopheles species (Roux et al., 2013; Roux et al., 2014). Mosquito larvae were provided with Tetramin ${ }^{\circledR}$ Baby Fish Food ad libitum twice a day and excess food was removed each day using a Pasteur pipette to avoid water pollution. Due to predator consumption, mosquito larval densities varied over time in the experimental containers. To avoid a potential density effects on adult life history traits (Alto, Lounibos, Higgs \& Juliano, 2005; Breaux, Schumacher \& Juliano, 2014), we standardized the larval density by randomly removing supernumerary larvae from the control containers on one occasion when larvae reached the late second instar. Indeed, most of the direct consumptive effect of predation occurs during early development (on first and second instar larvae). Later, predation rate decreases as larvae grow bigger (third and fourth instar) and changes in density due to consumptive effect of the predator becomes negligible (see results on emergence rate). To maintain larval density equivalent among experimental treatments and over the course of the experiment, mosquito larvae were counted in both predation and control containers by pairs, and the densities made equal between these pairs by removing the exceeding numbers of larvae from the corresponding controls. At the end of larval development, the pupae were collected and placed in plastic cups at equal densities for emergence in 30x 30x30 cm cages covered with a mesh. No water or glucose was provided. 


\section{Measurement of traits}

\section{Life history traits}

A series of life history traits susceptible of being affected by predation stress were measured; namely, mosquito development time, longevity, fecundity and adult size (Roux et al., 2015) (Fig. 1). Development time - This is the number of days from egg to adult emergence. Adults were collected once a day in the morning. Longevity - On the morning of adult emergence, forty $20 \times 20 \times 20 \mathrm{~cm}$ cages were set-up ( 5 for each sex, predator exposure, species combination). Ten individuals that emerged from the same container were placed into one cage, and mosquitoes were provided with water and 5\% glucose solution ad libitum $(=50$ mosquitoes per combination, $\mathrm{N}=400$ individuals). Dead individuals were counted and removed every $24 \mathrm{~h}$. Fecundity - On the morning of adult emergence, and for each species, predator exposure combination, 40 females were placed in a $30 \times 30 \times 30 \mathrm{~cm}$ cage with water and 5\% glucose solution ad libitum. At day 2 post emergence, females were starved for $12 \mathrm{~h}$, and were then offered a blood meal on the arm of a volunteer for 30 minutes on two consecutive days. An informed written consent was obtained from the volunteer. Females that were not fully engorged on the two occasions were discarded. Three days post-blood meal, ovaries of 35 randomly chosen females of each combination were dissected under a stereomicroscope (magnification 35x, Leica EZ4D, Wetzlar, Deutschland) and egg load, defined as the number of eggs in gravid females, was measured as a surrogate for fecundity. Adult size - in addition to ovaries, one wing per female was dissected, photographed and measured from the alular notch to the apical margin tip, excluding fringe scales as a proxy for adult size. Measurements were made with the ImageJ software (V1.47, Wayne Rasband National Institute of Health, USA). 
On the morning of adult emergence, mosquitoes which were not used for the life history trait study were frozen at $-80{ }^{\circ} \mathrm{C}$, and kept in the freezer until analysis. We measured teneral metabolic reserves (including the whole protein and lipid contents and nonconstitutive carbohydrates and amino acids), total anti-oxidant capacity (TAC), and oxidative damages on proteins (protein carbonyls). For analysis, pools of five randomly chosen mosquitoes of the same sex and belonging to the same container (=same species, predator exposure combination) were weighed (Mettler-Toledo MX-5 microbalance, Columbus, $\mathrm{OH}$, USA; $d=0.1 \mu \mathrm{g})$. These five-pooled mosquitoes were considered as a unique sample for the following analyses (Fig. 1).

Protein assays - Protein assays were conducted as described by Foray et al. (2012). Briefly, for each combination (species x sex x predator exposure), the pools of five mosquitoes were homogenized in $180 \mu \mathrm{L}$ of phosphate buffer for $90 \mathrm{~s}$ at $25 \mathrm{~Hz}$ using a beadbeating device (Retsch ${ }^{\mathrm{TM}}$ MM301, Retsch GbmH, Haan, Germany). Following low-spin centrifugation $\left(180 \mathrm{~g}, 4^{\circ} \mathrm{C}\right)$ to remove insect debris, a volume of $5 \mu \mathrm{L}$ of the supernatant was used to measure body protein content using Bradford's technique (Bradford, 1976). Absorbance of the samples was read at $595 \mathrm{~nm}$. The quantity of proteins was calculated from a bovine serum albumin (CAS number: 9048-46-8) calibration curve. The remaining $175 \mu \mathrm{L}$ of each sample were then used for the following physiological assays.

Carbohydrate and amino acid assays - In order to examine the effects of predation on the variation of the different metabolic families (amino acids, sugars) of each individual, the gas chromatography-mass spectrometry (GC-MS) platform was used, as described in Khodayari et al. (2013). A volume of $450 \mu \mathrm{L}$ of methanol-chloroform (ratio 2:1, volume:volume) was added to the remaining $175 \mu \mathrm{L}$ of mosquito homogenate obtained from protein assays and were homogenized using a bead-beating device at $25 \mathrm{~Hz}$ for $90 \mathrm{~s}$. Then, $125 \mu \mathrm{L}$ of ultrapure water was added to the samples that were then further centrifuged at 
$4000 \mathrm{~g}$, at $4{ }^{\circ} \mathrm{C}$, for $10 \mathrm{~min}$. An aliquot of the supernatant $(90 \mu \mathrm{L})$, which contained polar metabolites, was transferred to new microtubes, and the aliquots were vacuum-dried (Speed Vac Concentrator, MiVac, Genevac Ltd., Ipswich, United Kingdom). Dried samples were resuspended in $30 \mu \mathrm{L}$ of $20 \mathrm{mg} / \mathrm{mL}$ methoxyamine-hydrochloride in pyridine prior to incubation under orbital shaking at $40^{\circ} \mathrm{C}$ for $60 \mathrm{~min}$, as described in Dahirel et al. (2019). Following incubation, $30 \mu \mathrm{L}$ of $\mathrm{N}$-methyl-bis(trifluoroacetamine) (BSTFA) were added, and derivatisation was conducted at $40^{\circ} \mathrm{C}$ for $60 \mathrm{~min}$ under agitation. Then, $1 \mu \mathrm{L}$ of each sample was injected using the split mode $(25: 1)$ in the $\mathrm{GC}$ injector set at $260^{\circ} \mathrm{C}$. The oven, equipped with a 30m fused silica column (TR5 MS, I.D. $0.25 \mathrm{~mm}, 95 \%$ dimethyl siloxane, $5 \%$ phenyl polysilphenylene-siloxane) was programmed to remain at $70^{\circ} \mathrm{C}$ for $4 \mathrm{~min}$ and then increased at a rate of $5^{\circ} \mathrm{C} / \mathrm{min}$ until it reached $300^{\circ} \mathrm{C}$ for $10 \mathrm{~min}$. Helium was used as carrier gas at $1 \mathrm{~mL} / \mathrm{min}$. The temperatures of mass spectrometry transfer line and of the ion source were set at $260^{\circ} \mathrm{C}$. Detection was conducted by electronic impact method $(70 \mathrm{eV})$. Chromatograms were deconvoluted using XCalibur v2.0.7. Calibration curves were run for 62 pure reference compounds at concentrations of $1,2,5,10,20,50,100,200,500,750,1000$ and $1500 \mu \mathrm{M}$. The same carbohydrates and amino acids were detected in all samples, and were then pooled to run statistical comparisons among metabolic families. Both detailed quantitative and qualitative metabolomic data will be further analysed and used for addressing distinct research questions.

Lipid assays - The triglyceride assays were performed on the samples prepared for GC-MS analyses, and as recommended by the manufacturer of the triglyceride colorimetric assays (Triglycerides, kit reference CC02200, LTA srl, Italy). Briefly, a volume of $110 \mu \mathrm{L}$ of chloroform was collected for each sample which was subsequently dried under a fume hood for $24 \mathrm{~h}$. Then, the lipid droplet was re-dissolved into $150 \mu \mathrm{L}$ of Triton-BSA buffer $(750 \mathrm{mg}$ BSA, $50 \mu \mathrm{L}$ triton $100 \mathrm{X}, 25 \mathrm{~mL}$ ultrapure water) and incubated for $10 \mathrm{~min}$ at $60^{\circ} \mathrm{C}$ immediately 
before the assays. A volume of $10 \mu \mathrm{L}$ of the supernatant was used to measure triglycerides. Absorbance of the samples was read at $510 \mathrm{~nm}$.

Oxidative stress - Mosquitoes were homogenized individually according to the manufacturer's instructions (Cayman Chemical: Total antioxidant capacity, item No. 709001 and Protein carbonyl, item No. 10005020); the total antioxidant capacity and the oxidized proteins (protein carbonyls) were quantified on different mosquitoes. The total antioxidant capacity (TAC) measures the combination of the entire antioxidant system of the sample including enzymes and different molecules such as macromolecules and vitamins from endoor exogenous (diet) origins and thus represents the cumulative antioxidant capacity of the sample/organism. The TAC is measured and compared to an equivalent of trolox (vitamin $\mathrm{E}$ analogue) antioxidant activity.

The protein carbonyl is a marker of protein oxidation. Protein carbonyls are measured through a reaction with dinitrophenylhydrazine (DNHP) which form hydrazone detectable through spectrophotometric analyzes. The result is expressed as a proportion of oxidized proteins on the total protein content.

For each kit, we analyzed 8 individuals per sex, species and predator exposure combination $(\mathrm{N}=128)$.

\section{Statistical analyses}

Life history traits - During experiments, the origin of each mosquito (i.e. larval container) was tracked to be included as random factor in all analyses. Cox's mixed model was used to analyze larval development time and adult survivorship with predator exposure (yes or no), sex, species and their interactions coded as fixed effects. Mosquito weight and female wing size were analyzed separately with a linear-mixed model (LMM) with predator exposure, species, sex (in weight analysis only) and their interactions as fixed effect. Egg load 
was analyzed using a LMM with wing size, predator exposure and their interactions as fixed effects. As body mass and wing size were not measured on the same individuals (see Fig 1), they were not considered as covariates in longevity and fecundity analyses. To check for the reliability of our method to equalize larval densities between predator exposed and control containers, we analyzed the number of emerged adults with a Wilcoxon paired test. Physiological traits - Proteins, lipids, total antioxidant capacity, carbohydrates and amino acids were analyzed separately with a LMM with predator exposure, species, sex and their interactions as fixed effect. Protein carbonyls were considered as a fraction of total protein content and were analysed using a quasi-binomial generalized linear-mixed model (GLMM). Predator exposure, species, sex and their interactions were considered fixed effects. When necessary, row data were power transformed to meet normality and/or homogeneity of variance assumptions (box-cox transformation with the "powerTransform" function in the "car" package). For model selection, we used the stepwise removal of terms, followed by likelihood ratio tests (LRT). Term removals that significantly reduced explanatory power $(P<0.05)$ were retained in the minimal adequate model (Crawley, 2007). All analyses were conducted using the R software (v. 2.12.1).

\section{Results}

\section{Mosquito development, size and weight}

Among larvae exposed to predation, An. coluzzii survived better than An. gambiae with 772 out of 1500 larvae for An. coluzzii (51.5\%, mean \pm se survivors/container: $154 \pm 12$ ) and 693 out of 2100 larvae for An. gambiae (33\%, mean \pm se survivors/container: $99 \pm 6$ ) $\left(X^{2}=122 ; P<0.001\right)$. After correction of densities, 756 control larvae of An. coluzzii $(50.4 \%$, mean \pm se survivors/container: $151 \pm 8)$ and 821 control larvae of An. gambiae (39.1\%, mean \pm se 
survivors/container: $117 \pm 2$ ) were obtained, which was not statistically different from exposed larvae containers $(W=9 ; P=0.8$ and $\mathrm{W}=3 ; P=0.08$, respectively).

The mean $( \pm$ s.e. $)$ larval developmental time of survivors was significantly affected by the interaction between predator exposure and species $\left(X^{2}{ }_{1}=8 ; P=0.004\right)$. Exposed larvae of An. coluzzii had a longer period of development than their controls $(11.1 \pm 0.02 v s .10 .6 \pm 0.02$ days; $\left.X^{2}=10.5 ; P=0.001\right)$ while no significant difference was found between exposed and control larvae of An. gambiae (10.5 \pm 0.03 vs. $10.5 \pm 0.03$ days; $\left.X^{2}{ }_{1}=0.3 ; P=0.5\right)$. Males emerged earlier than females $\left(10.61 \pm 0.02\right.$ vs. $10.71 \pm 0.02$ days; $X^{2}{ }_{1}=11.3 ; P<0.001$; Fig. $\left.2 \mathrm{a}\right)$, regardless of predator exposure (i.e. no sex X predator exposure interaction; $X_{1}{ }_{1}=0.81 ; P=0.3$ ). There was no significant effect for other interactions (species $\mathrm{X}$ sex: $X^{2}{ }_{1}=0.65 ; P=0.4$ and species $\mathrm{X}$ sex X predator exposure: $\left.X^{2}=0.55 ; P=0.4\right)$.

Predator exposure also influenced mean $( \pm$ s.e. $)$ adult body size in the two species. Females that emerged from larvae exposed to predators had significantly shorter wings than their control counterparts $(3229 \pm 15 v s .3361 \pm 18 \mu \mathrm{m}$ in An. coluzzii and $3428 \pm 23 v s$. $3521 \pm 21 \mu \mathrm{m}$ in An. gambiae, $X^{2}{ }_{1}=13.32 ; P<0.001$; Fig. 2b). Females of An. coluzzii were smaller than those of $A n$. gambiae ( $3296 \pm 14 v$ s. $3475 \pm 17 \mu \mathrm{m}$, respectively, $X^{2}{ }_{1}=26.2$; $P<0.001)$. There was no significant interaction between species and predator exposure $\left(X_{1}^{2}=0.5 ; P=0.4\right)$.

Mosquito mean ( \pm s.e.) body weight was significantly affected by the interaction between predator exposure and species $\left(X^{2}{ }_{1}=4.3 ; P=0.03\right)$, thus $A n$. gambiae adults from exposed larvae were lighter than their controls $(1.27 \pm 0.02 \mathrm{mg} v s .1 .36 \pm 0.02 \mathrm{mg}$, respectively; $X^{2}{ }_{1}=13.5 ; P<0.001$; Fig. $2 \mathrm{c}$ ), while no significant differences were detected between exposed and control groups for An. coluzzii (1.37 $\pm 0.02 \mathrm{mg} v s .1 .40 \pm 0.02 \mathrm{mg}$, respectively; $X^{2}{ }_{1}=1.15$; $P=0.28)$. Females were heavier than males $(1.47 \pm 0.01$ vs. $1.23 \pm 0.01 \mathrm{mg}$, respectively; $\left.X^{2}=186 ; P<0.001\right)$. There was no other significant interaction (sex $\mathrm{X}$ species: $X^{2}{ }_{1}=2.3$; 
$P=0.12$; sex:predator exposure: $X^{2}{ }_{1}=0.6 ; P=0.43$ and species $\mathrm{X}$ sex $\mathrm{X}$ predator exposure: $\left.X^{2}=0.05 ; P=0.8\right)$

\section{Mosquito fecundity}

After two blood meals, all females were gravid. The mean egg load ( \pm s.e.) was negatively affected by exposure to predators ( $159 \pm 5$ eggs in predator-exposed $v s .180 \pm 6$ eggs in control; $X_{1}{ }_{1}=4.7 ; P=0.02$; fig. $2 \mathrm{~d}$ ). Anopheles coluzzii had more eggs than An. gambiae (205 \pm 4 vs. $136 \pm 4$ eggs, respectively; $\left.X^{2}{ }_{1}=59 ; P<0.001\right)$. Finally, egg load was positively associated with wing size $\left(X^{2}{ }_{1}=14 ; P<0.001 ;\right.$ Fig. 3$)$. There was no significant interaction (predator exposure $\mathrm{X}$ wing size: $X^{2}{ }_{1}=3.6 ; P=0.057$; predator exposure $\mathrm{X}$ species: $X^{2}{ }_{1}=0.4$; $P=0.5$; species $\mathrm{X}$ wing size: $X^{2}{ }_{1}=0.2 ; P=0.6$; predator exposure $\mathrm{X}$ species $\mathrm{X}$ wing size: $\left.X^{2}=0.7 ; P=0.4\right)$.

\section{Mosquito longevity}

Adults emerged from predator-exposed or control larvae had the same longevity ( $30 \pm 0.7$ vs. $28.5 \pm 0.8$ days, $\mathrm{N}=20$ cages each; $\left.X^{2}{ }_{1}=0.1 ; P=0.7\right)$ and no interaction was found between predator exposure and sex, or between predator exposure and species $\left(X^{2}{ }_{1}=0.62\right.$; $P=0.43, X^{2}=0.15 ; P=0.69$, respectively). However, the interaction between sexes and species was significant $\left(X^{2}=14.4 ; P<0.001\right.$; Fig. 4): males surpassed females at surviving in $A n$. coluzzii (26.7 \pm 1 vs. $19.3 \pm 0.9$ days, $\mathrm{N}=100$ and 99 , respectively; $\left.X^{2}=22.2 ; P<0.001\right)$, whereas males of An. gambiae only slightly survived better than females ( $36.3 \pm 0.7$ vs. $34.7 \pm 0.7$ days, $\mathrm{N}=100$ and 100 , respectively; $X^{2}{ }_{1}=4.3 ; P=0.037$ ). 
Mean ( \pm s.e.) protein content was similar in the two species $(31.8 \pm 0.7 v s$.

$32.6 \pm 0.5 \mu \mathrm{g} / \mathrm{mg}$ in An. coluzzii and An. gambiae, respectively; $X^{2}=1.4 ; P=0.2 ;$ Fig. 5a).

However, there was a significant interaction between sex and predator exposure $\left(X^{2}{ }_{1}=10.9\right.$;

$P<0.001)$, predator-exposed females had lower protein content than their control counterparts (30 $\pm 0.7 v s .34 \pm 0.7 \mu \mathrm{g} / \mathrm{mg}$, respectively; $\left.X^{2}{ }_{1}=124 ; P<0.001\right)$, while no significant difference was found between predator-exposed and control males $(33 \pm 0.7 v s .31 .7 \pm 0.9 \mu \mathrm{g} / \mathrm{mg}$, respectively; $X_{1}{ }_{1}=1.05 ; P=0.3$ ). There was no significant effect for other interactions (species $\mathrm{X}$ sex: $X^{2}{ }_{1}=0.9 ; P=0.3$; predator exposure $\mathrm{X}$ species: $X^{2}{ }_{1}=0.7 ; P=0.3$ and predator exposure $\mathrm{X}$ species $\mathrm{X}$ sex: $\left.X^{2}{ }_{1}=2.8 ; P=0.09\right)$.

Mean ( \pm s.e.) lipid content was significantly affected by the interaction between species, sex and predator exposure $\left(X^{2}{ }_{1}=8.6 ; P=0.003\right.$; Fig. 5b). Species subset analysis showed that in An. coluzzii, predator exposed mosquitoes had almost twice more lipids than controls (9.6 $\pm 0.6 v s .4 .9 \pm 1.2 \mu \mathrm{g} / \mathrm{mg}$, respectively; $\left.X^{2}{ }_{1}=14.4 ; P<0.001\right)$ and that sex had no effect (males: $8.2 \pm 1 \mu \mathrm{g} / \mathrm{mg} v$. females: $6.2 \pm 1.2 \mu \mathrm{g} / \mathrm{mg}, X^{2}{ }_{1}=2.3 ; P=0.12$ ). In An. gambiae, lipid content was significantly affected by the interaction between predator exposure and sex $\left(X^{2}=7.3 ; P=0.006\right)$. Females exposed to predation stress as larvae had a lower lipid content than control $\left(5.2 \pm 0.7 v s .7 .5 \pm 0.9 \mu \mathrm{g} / \mathrm{mg}\right.$, respectively; $\left.X_{1}{ }_{1}=21 ; P=0.02\right)$ while no significant difference was detected in males (predator exposed: $6.7 \pm 0.3 \mu \mathrm{g} / \mathrm{ml} v s$. control: $5.3 \pm 1.2 \mu \mathrm{g} / \mathrm{mg}$; $\left.X^{2}=8 ; P=0.2\right)$.

The mean $( \pm$ s.e. $)$ carbohydrate content was negatively affected by predator exposure. Exposed individuals had a lower carbohydrate content than controls $(76.3 \pm 5.8 v s .92 .5 \pm 5.6$ $\mathrm{nmol} / \mathrm{mg}$, respectively; $X^{2}=7.01 ; P=0.008 ;$ Fig: $\left.5 \mathrm{c}\right)$. Females had significantly fewer carbohydrates than males $\left(70.3 \pm 3.8 v s .97 .1 \pm 6.1 \mathrm{nmol} / \mathrm{mg}\right.$, respectively; $\left.X^{2}{ }_{1}=26.5 ; P<0.001\right)$ and An. gambiae had a lower carbohydrate content than An. coluzzii $(68 \pm 4.1$ vs. $102.8 \pm 5.5$ $\mathrm{nmol} / \mathrm{mg}$, respectively; $\left.X^{2}{ }_{1}=16.2 ; P<0.001\right)$. There was no significant effect of interactions 
(species X sex: $X^{2}=1.3 ; P=0.2$; predator exposure $\mathrm{X}$ species: $X^{2}{ }_{1}=2.4 ; P=0.1$; predator exposure $\mathrm{X}$ sex: $X^{2}{ }_{1}=0.04 ; P=0.8$ and predator exposure $\mathrm{X}$ species $\mathrm{X}$ sex: $\left.X^{2}{ }_{1}=0.64 ; P=0.4\right)$. The mean ( \pm s.e. $)$ amino acid content was negatively affected by predator exposure. Exposed individuals had a lower amino acid content than controls $(74.2 \pm 6.4$ vs. $90.7 \pm 6.5$ $\mathrm{nmol} / \mathrm{mg}$, respectively; $X^{2}{ }_{1}=5 ; P=0.02$; Fig: $\left.5 \mathrm{~d}\right)$. Females had significantly more amino acids than males (106.6 \pm 5.4 vs. $62.3 \pm 4.6 \mathrm{nmol} / \mathrm{mg}$, respectively; $\left.X^{2}=51 ; P<0.001\right)$, and $A n$. gambiae had a lower amino acid content than An. coluzzii $(68.5 \pm 5.9$ vs. $98.2 \pm 6 \mathrm{nmol} / \mathrm{mg}$, respectively; $X^{2}{ }_{1}=17.9 ; P<0.001$ ). There was no significant effect of interactions (species $\mathrm{X}$ sex: $X^{2}{ }_{1}=0.5 ; P=0.5$; predator exposure $\mathrm{X}$ species: $X^{2}{ }_{1}=0.3 ; P=0.5$; predator exposure $\mathrm{X}$ sex: $X^{2}=1.88 ; P=0.2$ and predator exposure $\mathrm{X}$ species $\mathrm{X}$ sex: $\left.X^{2}{ }_{1}=1.04 ; P=0.3\right)$.

\section{Oxidative status}

Individuals exposed to predation stress had a lower mean $( \pm$ s.e. $)$ total anti-oxidant capacity than controls $\left(20.6 \pm 0.8 \mu \mathrm{M} / \mathrm{mg}\right.$ vs. $23.8 \pm 0.7 \mu \mathrm{M} / \mathrm{mg}$, respectively; $X^{2}=7.1 ; P=0.007$; Fig. 6a). An. gambiae had a lower total anti-oxidant capacity than An. coluzzii (20.5 $\pm 0.6 \mu \mathrm{M} / \mathrm{mg}$ vs. $23.8 \pm 0.9 \mu \mathrm{M} / \mathrm{mg}$, respectively; $\left.X^{2}{ }_{1}=7.5 ; P=0.006\right)$. There was no significant effect of sex (males: $22.1 \pm 1 \mu \mathrm{M} / \mathrm{mg} v$ s. females: $22.1 \pm 0.7 \mu \mathrm{M} / \mathrm{mg} ; X^{2}{ }_{1}=0.0002$; $P=0.98$ ) or interaction (predator exposure $\mathrm{X}$ sex $\mathrm{X}$ species: $X^{2}{ }_{1}=0.1 ; P=0.7$; predator exposure $\mathrm{X}$ sex: $X^{2}=0.4 ; P=0.5$; predator exposure $\mathrm{X}$ species: $X^{2}{ }_{1}=0.08 ; P=0.8$; sex X species: $\left.X^{2}{ }_{1}=0.06 ; P=0.8\right)$.

The mean $( \pm 95 \% \mathrm{CI})$ carbonyl proportion was significantly affected by the interaction between species, sex and predator exposure $\left(X^{2}{ }_{1}=5.6 ; P=0.017\right.$; Fig. $\left.6 \mathrm{~b}\right)$. Species subset analysis showed that in An. coluzzii, neither predator exposure nor sex or their interaction had a significant effect on carbonyl proportion $\left(X^{2}{ }_{1}=1.24, P=0.3 ; X^{2}=0.5, P=0.5\right.$ and $X^{2}{ }_{1}=0.5$, $P=0.5$, respectively). In An. gambiae, the proportion of carbonyl was significantly affected by 
the interaction between predator exposure and sex. Male exposed to predation stress during their larval development had a higher carbonyl proportion than control males $(0.15 \pm 0.004 v s$. $0.11 \pm 0.02$, respectively) while exposed females had a lower carbonyl proportion than control females $(0.05 \pm 0.03$ vs. $0.11 \pm 0.03$, respectively).

\section{Discussion}

Behavioral and physiological responses to life-threatening stress are supposed to increase immediate individual survival (Hawlena \& Schmitz, 2010). During such episodes, and according to the general stress paradigm (Hawlena \& Schmitz, 2010), both nutrition and respiration can be altered, lowering resource acquisition and increasing the chances of oxidative stress.

In the An. gambiae complex, both An. coluzzii and An. gambiae s.s. larvae exposed to a predation risk adopted a less conspicuous behavior to avoid their detection by predators, but did not reduce the time spent to feed (Roux et al., 2013). In this study, predator exposed $A n$. coluzzii larvae, which are adapted to high predator densities, took more time to develop than their control relatives. Larval survival during prolonged exposure to predation risk is possible through an anti-predator behavior proportional to the threat level (Roux et al., 2014). In our experimental conditions, it allows individuals to reach the same weight at emergence as controls but with a smaller wing size. This finding is in line with earlier studies conducted on Aedes notoscriptus and Culex pipiens exposed to fishes and backswimmer, respectively (Beketov \& Liess, 2007; van Uitregt, Hurst \& Wilson, 2012). A disequilibrium in allometric relationship between body mass and wing size was also observed in Aedes albopictus exposed to stressful conditions (Reiskind \& Zarrabi, 2012) showing that wing size is not an appropriate proxy of mosquito weight for larval stressful environments. 
Interestingly, An. gambiae larvae exposed to predators were characterized by a similar

developmental duration than their respective controls, which resulted in both smaller body mass and wing size at emergence. This strategy of fast growth (compared to An. coluzzii), which supposedly decreases the time of exposure to predation threat, might reveal the lower level of adaptation of these larvae to the presence of predators (Diabaté et al., 2008;

Gimonneau et al., 2012b; Roux et al., 2013; Roux et al., 2014). Since both species do not seem to change their feeding rates (Roux et al., 2013), it is likely that these strategies are resource consuming and/or alter nutrient assimilation or allocation which would explain differences in weight or in wing size (growth-predation risk trade-off, McPeek et al., 2001; Stoks et al., 2005).

Compared to controls, a reduced fecundity was observed in both An. gambiae and An. coluzzii exposed to predator as larvae, thus suggesting that female reduced size cannot be the only explanation for this pattern. In An. gambiae females, the fast development under predation threat and/or the induced stress have resulted in a reduction of all of the possible energy sources (proteins: $-10 \%$, amino acids: $-27 \%$, lipids: $-31 \%$ and carbohydrates: $-31 \%$ ). In An. coluzzii females however, only protein stocks were depleted (-14\%) while lipid reserves were increased $(+73 \%)$. These quantities were analyzed at adult emergence, and the observed difference in terms of fecundity, despite the two blood meals and glucose provided ad libitum during 7 days, suggests that female fecundity also greatly depends on their preexisting resources acquired during larval development to produce the first batch of eggs (Briegel, 1990; Briegel, Hefti \& DiMarco, 2002; Zhou et al., 2004). This dependence between larval resources and fecundity was already demonstrated in Aedes aegypti, in which a large amount of larval derived lipid and carbohydrates reserves are used to produce the first egg batch (Zhou et al., 2004). Amino acids are also known to be essential to the initiation of ovarian 
development and their concentration in hemolymph is positively correlated to the number of eggs produced (Uchida et al., 2001).

Carbohydrates are known to be the metabolites that fuel flight in most insects (Sacktor, 1955; Nayar \& Sauerman, 1971), flying capacities being highly important in Anopheles species for mating. Indeed, males form swarms at dusk in which they are in competition for females and a longer swarming activity increases the male's competitiveness (Yuval, Holliday-Hanson \& Washing, 1994). Swarming behavior can consume more than $50 \%$ of the individual's carbohydrate reserves (Yuval et al., 1994; Maiga et al., 2014), and males with low levels of carbohydrates do not participate in mating (Yuval et al., 1994; Yuval, Kaspi, Shloush \& Warburg, 1998). Even if carbohydrates reserves can be replenished while feeding on sugar (mainly flower nectars), having a large amount of energy available directly at emergence may allow males to actively participate to swarming as soon as they are mature (about $24 \mathrm{~h}$ after emergence). All together, it may explain why males had more carbohydrates than females at emergence.

Carbohydrate reserves were similar in both controls and exposed An. coluzzii males while they were lowered in exposed An. gambiae males (-29\%). Consumption of short-term energy metabolites, including carbohydrates, increases under stressful conditions in order to support responses like fight-or-flight strategy (McPeek et al., 2001; Hawlena \& Schmitz, 2010; Van Dievel et al., 2016). Here, An. coluzzii, which spends more time in less conspicuous locations than An. gambiae (Roux et al., 2014), might also have evolved a lower metabolite rate that would reduce the consumption of body carbohydrates. Conversely, $A n$. gambiae which is less adapted than An. coluzzii to the presence of predators (Diabaté et al., 2008) needs to be ready to develop a fight-or-flight response and consequently could consume more energy. 
According to the general stress paradigm (Hawlena \& Schmitz, 2010), exposure to

470

471

472

473

474

475

476

477

478

479

480

481

482

483

484

485

486

487

predation stress increases metabolic rates and oxygen consumption to make the body ready for a fight-or-flight response (emergency functions) which consequently accentuates the alteration of teneral reserve accumulation, and may increase the risk of oxidative stress. Our results show a decrease in the total antioxidant capacity in the two sexes of the two mosquito species exposed to predation risk. Such a decrease or absence of variation in antioxidant capacity during chronic stress was already observed in damselflies (Slos \& Stoks, 2008; Janssens \& Stoks, 2013), Corixids (Trekels, Van de Meutter, Bervoets \& Stoks, 2012) and amphipods (Jermacz et al., 2020a; Jermacz, Nowakowska, Kletkiewicz \& Kobak, 2020b), and was described as a mechanism to reduce the cost of production of antioxidant response which cannot be sustained for long. Three scenarios could explain these results. In the first, larvae could reduce their metabolic rate due to the habituation to predation threat cues (Ferrari, Elvidge, Jackson, Chivers \& Brown, 2010; Roux et al., 2014) and/or to reduce costs due to the production of reactive oxygen species (ROS) and antioxidant molecules (Jermacz et al., 2020a). Late instar larvae which reset their activity would be more vulnerable to predator attacks unless their larger sizes dissuaded predators. In the second scenario, larvae could reconfigure their physiology to conserve both an increased metabolism and their ability to develop a fight-or-flight response, while reducing costs related to a higher ROS level (Jermacz et al., 2020a; Jermacz et al., 2020b). In the third scenario, individuals could adjust their levels of defense to maintain a certain level of damages (Janssens \& Stoks, 2013). In all these scenarios, the capacity to repair or replace damaged molecules should also be considered since it could be energetically 'cheaper' than trying to avoid oxidation (Halliwell \& Gutteridge, 2007).

In our study, late instar larvae still produce anti-predator behavior by staying on the wall of the container (pers. obs.), we however did not control for metabolic rate. Moreover, 
we did not look at other potential damages on lipids and DNA. In addition, we chose to look at protein damages during the emergence of adults, just after metamorphose during which a lot of molecules are lysed and could be eliminated or repaired if oxidized (Campero, De Block, Ollevier \& Stoks, 2008). This choice to investigate carry-over effects is relevant but may mask oxidative/antioxidant mechanisms at work during larval development.

Finally, none of the changes recorded in metabolic reserves or in oxidative status affects longevity. Nevertheless, some carry-over effects of predation on longevity are detectable in more challenging situations such as under low food regimen (Roux et al., 2015).

To summarize, as expected, larval predation stress affected negatively some life history traits and all the nutritional reserves analyzed. This highlights a potential priorization of nutrient assimilation to fulfill some fitness traits or to fuel a fight-or-flight anti-predator behavior according to the species' degree of adaptation to the level of predation threat. We expected a higher level of Total Antioxidant Capacity but the contrary was observed, without an increased oxidation of proteins (except for An. gambiae males). This result could be an adaptation to chronic stress to decrease the cost of long-term exposure. Overall, our results revealed that An. coluzzii may suffer less from predation stress, or at least managed differently nutrient assimilation than An. gambiae does under predation threat, which could be due to their respective ecology.

To conclude, during the last decade, evolutionary ecologists have attempted to conceptualize the links between oxidative stress, resource allocations and life history traits in the oxidative stress hypothesis of life history (Dowling \& Simmons, 2009; Monaghan et al., 2009; Selman et al., 2012; Speakman et al., 2015; Costantini, 2019). However, despite growing evidence that oxidative stress might play a significant role in physiological adaptive responses to environmental stressors and in evolutionary trajectories, questions like "How do 
519 stress responses vary between species or sex?" remain unresolved. Our results provide

520 evidence that even between closely related species and between sexes, physiological

521 responses, life histories and oxidative status can be very different and complex.

\section{CRediT authorship contribution statement}

524 Olivier Roux: Conceptualization, Methodology, Data collection, Formal analyses and

Writing- original draft; Karine Mouline: Methodology, Data collection; Frederic Simard:

526

527

Conceptualization and Funding acquisition; David Renault: Data collection and Writingoriginal draft preparation. All authors contributed critically to the drafts and gave final approval for publication.

Acknowledgements: We would like to thank B. Nikiema for the RFLP-PCR, C. Brengues and A. Milesi for preliminary analysis and Heidi Lançon for proofreading the paper.

Funding: This work was supported by the DS3MAL grant attributed to FS by the French National Research Agency (ANR DS3-MAL). OR received financial support through a postdoctoral fellowship from the IRD. The physiological analyses were conducted on the equipment of the Analytical platform EcoChim from UMR CNRS 6553 EcoBio.

\footnotetext{
Competing interests: Authors have no competing interests to declare
} 


\section{References}

542

543 Alto, B. W., Lounibos, L. P., Higgs, S. \& Juliano, S. A. (2005). Larval competition

544

545

546

547

548

549

550

551

552

553

554

555

556

557

558

559

560 differentially affects arbovirus infection in Aedes mosquitoes. Ecology, 86, 32793288. doi: 10.1890/05-0209

Beketov, M. A. \& Liess, M. (2007). Predation risk perception and food scarcity induce alterations of life-cycle traits of the mosquito Culex pipens. Ecological Entomology, 32, 405-410. doi: 10.1111/j.1365-2311.2007.00889.x

Benard, M. F. (2004). Predator-induced phenotypic plasticity in organisms with complex life histories. Annual Review of Ecology, Evolution, and Systematics, 35, 651-673. doi: 10.1146/annurev.ecolsys.35.021004.112426

Benard, M. F. \& Fordyce, J. A. (2003). Are induced defenses costly? Consequences of predator-induced defenses in western toads, Bufo boreas. Ecology, 84, 68-78. doi: 10.1890/0012-9658(2003)084[0068:aidcco]2.0.co;2

Boggs, C. L. (1981). Nutritional and life-history determinants of resource allocation in holometabolous insects. American Naturalist 117, 692-709. doi: 10.1086/283753

Bradford, M. M. (1976). A rapid and sensitive method for the quantitation of microgram quantities of protein utilizing the principle of protein-dye binding. Annales of Biochemistry, 72, 248-254. doi: 10.1016/0003-2697(76)90527-3

Breaux, J. A., Schumacher, M. K. \& Juliano, S. A. (2014). What does not kill them makes them stronger: larval environment and infectious dose alter mosquito potential to transmit filarial worms. Proceedings of the Royal Society B: Biological Sciences, 281, 20140459. doi: 10.1098/rspb.2014.0459 
Briegel, H. (1990). Fecundity, metabolism, and body size in Anopheles (Diptera: Culicidae), vectors of malaria. Journal of Medical Entomology, 27, 839-850. doi: $10.1093 /$ jmedent/27.5.839

Briegel, H., Hefti, M. \& DiMarco, E. (2002). Lipid metabolism during sequential gonotrophic cycles in large and small female Aedes aegypti. Journal of Insect Physiology, 48, 547554. doi: 10.1016/S0022-1910(02)00072-0

Campero, M., De Block, M., Ollevier, F. \& Stoks, R. (2008). Metamorphosis offsets the link between larval stress, adult asymmetry and individual quality. Functional Ecology, 22, 271-277. doi: 10.1111/j.1365-2435.2007.01381.x

Costantini, D. (2008). Oxidative stress in ecology and evolution: lessons from avian studies. Ecology Letters, 11, 1238-1251. doi: 10.1111/j.1461-0248.2008.01246.x

Costantini, D. (2014). Oxidative stress and hormesis in evolutionary ecology and physiology. A marriage between mechanistic and evolutionary approaches., Berlin Heidelberg, Springer.

Costantini, D. (2019). Understanding diversity in oxidative status and oxidative stress: the opportunities and challenges ahead. The Journal of Experimental Biology, 222, jeb194688. doi: 10.1242/jeb.194688

Crawley, M. J. (2007). The R book, John Wiley \& Sons, Ltd.

Crean, J. A., Monro, K. \& Marshall, D. J. (2011). Fitness consequences of larval traits persist across the metamorphic boundary. Evolution, 65, 3079-3089. doi: 10.1111/j.15585646.2011.01372.x

Dahirel, M., Masier, S., Renault, D. \& Bonte, D. (2019). The distinct phenotypic signatures of dispersal and stress in an arthropod model: from physiology to life history. The Journal of Experimental Biology, 222, jeb203596. doi: 10.1242/jeb.203596 
De Block, M. \& Stoks, R. (2005). Fitness effects from egg to reproduction: Bridging the life history transition. Ecology, 86, 185-197. doi: 10.1890/04-0116

Diabaté, A., Dabiré, R. K., Heidenberger, K., Crawford, J., Lamp, W. O., Culler, L. E. \& Lehmann, T. (2008). Evidence for divergent selection between the molecular forms of Anopheles gambiae: role of predation. BMC Evolutionary Biology, 8, 5. doi: $10.1186 / 1471-2148-8-5$

Dowling, D. K. \& Simmons, L. W. (2009). Reactive oxygen species as universal constraints in life-history evolution. Proceedings of the Royal Society B: Biological Sciences, 276, 1737-1745. doi: 10.1098/rspb.2008.1791

Ferrari, M. C. O., Elvidge, C. K., Jackson, C. D., Chivers, D. P. \& Brown, G. E. (2010). The responses of prey fish to temporal variationin predation risk: sensory habituation or risk assessment? Behavioral Ecology 21, 532-536. doi: 10.1093/beheco/arq023

Ferrari, M. C. O., Messier, F. \& Chivers, D. P. (2008). Variable predation risk and the dynamic nature of mosquito antipredator responses to chemical alarm cues. Chemoecology, 17, 223-229. doi: 10.1007/s00049-007-0380-1

Foray, V., Pelisson, P. F., Bel-Venner, M. C., Desouhant, E., Venner, S., Menu, F., Giron, D. ... (2012). A handbook for uncovering the complete energetic budget in insects: the van Handel's method (1985) revisited. Physiological Entomology, 37, 295-302. doi: $10.1111 / \mathrm{j} .1365-3032.2012 .00831 . x$

Gimonneau, G., Bouyer, J., Morand, S., Besansky, N. J., Diabate, A. \& Simard, F. (2010). A behavioral mechanism underlying ecological divergence in the malaria mosquito Anopheles gambiae. Behavioral Ecology, 21, 1087-1092. doi: 10.1093/beheco/arq114 Gimonneau, G., Pombi, M., Choisy, M., Morand, S., Dabiré, R. K. \& Simard, F. (2012a). Larval habitat segregation between the molecular forms of the mosquito Anopheles 

gambiae in a rice field area of Burkina Faso, West Africa. Medical and Veterinary Entomology, 26, 9-17. doi: 10.1111/j.1365-2915.2011.00957.x

Gimonneau, G., Pombi, M., Dabire, R. K., Diabate, A., Morand, S. \& Simard, F. (2012b). Behavioural responses of Anopheles gambiae sensu stricto $\mathrm{M}$ and $\mathrm{S}$ molecular form larvae to an aquatic predator in Burkina Faso. Parasites \& Vectors, 5, 11. doi: $10.1186 / 1756-3305-5-65$

Guerra, C., Zenteno-Savín, T., Maeda-Martínez, A. N., Abele, D. \& Philipp, E. E. R. (2013). The effect of predator exposure and reproduction on oxidative stress parameters in the Catarina scallop Argopecten ventricosus. Comparative Biochemistry and Physiology Part A: Molecular \& Integrative Physiology, 165, 89-96. doi: 10.1016/j.cbpa.2013.02.006

Halliwell, B. \& Gutteridge, J. M. C. (2007). Oxidative stress and redox regulation: adaptation, damage, repair, senescence, and death. In B. Halliwell \& J. M. C. Gutteridge (Eds.), Free radicals in biology and medicine (pp. 199-293). New York U.S.A., Oxford University Press.

Hawlena, D. \& Schmitz, O. J. (2010). Physiological stress as a fundamental mechanism linking predation to ecosystem functioning. The American Naturalist, 176, 537-556. doi: $10.1086 / 656495$

Janssens, L. \& Stoks, R. (2013). Predation risk causes oxidative damage in prey. Biology Letters, 9doi: 10.1098/rsbl.2013.0350

Janssens, L. \& Stoks, R. (2014). Chronic predation risk reduces escape speed by increasing oxidative damage: A deadly cost of an adaptive antipredator response. PLoS One, 9, e101273. doi: 10.1371/journal.pone.0101273 
635

636

637

638

639

640

641

642

643

644

645

646

647

648

649

650

651

652

653

654

655

656

657

Jermacz, Ł., Kletkiewicz, H., Nowakowska, A., Dzierżyńska-Białończyk, A., Klimiuk, M. \& Kobak, J. (2020a). Continuity of chronic predation risk determines changes in prey physiology. Scientific Reports, 10, 6972. doi: 10.1038/s41598-020-64000-9

Jermacz, Ł., Nowakowska, A., Kletkiewicz, H. \& Kobak, J. (2020b). Experimental evidence for the adaptive response of aquatic invertebrates to chronic predation risk. Oecologia, 192, 341-350. doi: 10.1007/s00442-020-04594-z

Khodayari, S., Moharramipour, S., Larvor, V., Hidalgo, K. \& Renault, D. (2013). Deciphering the metabolic changes associated with diapause syndrome and cold acclimation in the two-spotted spider mite Tetranychus urticae. Plos One, 8, e54025. doi:

10.1371/journal.pone.0054025

Lima, S. L. (1998). Nonlethal effects in the ecology of predator-prey interactions. BioScience, 48, 25-34. doi: 10.2307/1313225

Lima, S. L. \& Dill, L. M. (1990). Behavioral decisions made under the risk of predation: a review and prospectus. Canadian Journal of Zoology, 68, 619-640. doi: 10.1139/z90092

Maiga, H., Niang, A., Sawadogo, S., Dabiré, R. K., Lees, R. S., Gilles, J., Tripet, F. ... (2014). Role of nutritional reserves and body size in Anopheles gambiae males mating success. Acta Tropica, 132, S102-S107. doi: 10.1016/j.actatropica.2013.08.018

McCauley, S. J., Rowe, L. \& Fortin, M.-J. (2011). The deadly effects of "nonlethal" predators. Ecology, 92, 2043-2048. doi: 10.1890/11-0455.1

McPeek, M. A., Grace, M. \& Richardson, J. M. L. (2001). Physiological and behavioral responses to predators shape the growth/predation risk trade-off in damselflies. Ecology, 82, 1535-1545. doi: 10.1890/0012-9658(2001)082[1535:pabrtp]2.0.co;2 
658

659

660

661

662

663

664

665

666

667

668

669

670

671

672

673

674

675

676

677

678

679

680

Metcalfe, N. B. \& Alonso-Alvarez, C. (2010). Oxidative stress as a life-history constraint: the role of reactive oxygen species in shaping phenotypes from conception to death. Functional Ecology, 24, 984-996. doi: 10.1111/j.1365-2435.2010.01750.x

Monaghan, P., Metcalfe, N. B. \& Torres, R. (2009). Oxidative stress as a mediator of life history trade-offs: mechanisms, measurements and interpretation. Ecology Letters, 12, 75-92. doi: 10.1111/j.1461-0248.2008.01258.x

Nayar, J. K. \& Sauerman, D. M. (1971). Physiological effects of carbohydrates on survival, metabolism, and flight potential of female Aedes taeniorhynchus. Journal of Insect Physiology, 17, 2221-2233. doi: 10.1016/0022-1910(71)90180-6

Pechenik, J. A. (2006). Larval experience and latent effects - metamorphosis is not a new beginning. Integrative and Comparative Biology, 46, 323-333. doi: 10.1093/icb/icj028

Pinya, S., Tejada, S., Capó, X. \& Sureda, A. (2016). Invasive predator snake induces oxidative stress responses in insular amphibian species. Science of the Total Environment, 566, 57-62. doi: 10.1016/j.scitotenv.2016.05.035

Preisser, E. L., Bolnick, D. I. \& Benard, M. F. (2005). Scared to death? The effects of intimidation and consumption in predator-prey interactions. Ecology, 86, 501-509. doi: doi:10.1890/04-0719

Reiskind, M. H. \& Zarrabi, A. A. (2012). Is bigger really bigger? Differential responses to temperature in measures of body size of the mosquito, Aedes albopictus. Journal of Insect Physiology, 58, 911-917. doi: 10.1016/j.jinsphys.2012.04.006

Roux, O., Diabate, A. \& Simard, F. (2013). Larvae of cryptic species of Anopheles gambiae respond differently to cues of predation risk. Freshwater Biology, 58, 1178-1189. doi: $10.1111 /$ fwb. 12117 
681

682

683

684

685

686

687

688

689

690

691

692

693

694

695

696

697

698

699

700

701

702

703

Roux, O., Diabate, A. \& Simard, F. (2014). Divergence in threat sensitivity among aquatic larvae of cryptic mosquito species. Journal of Animal Ecology, 83, 702-711. doi: $10.1111 / 1365-2656.12163$

Roux, O., Vantaux, A., Roche, B., Yameogo, K. B., Dabiré, K. R., Diabaté, A., Simard, F. ... (2015). Evidence for carry-over effects of predator exposure on pathogen transmission potential. Proceedings of the Royal Society B: Biological Sciences, 282, 2430. doi: 10.1098/rspb.2015.2430

Sacktor, B. (1955). Cell structure and the metabolism of insect flight muscle. The Journal of biophysical and biochemical cytology, 1, 29-46. doi: 10.1083/jcb.1.1.29

Santolamazza, F., Mancini, E., Simard, F., Qi, Y., Tu, Z. \& della Torre, A. (2008). Insertion polymorphisms of SINE200 retrotransposons within speciation islands of Anopheles gambiae molecular forms. Malaria Journal, 7, 163. doi: 10.1186/1475-2875-7-163

Selman, C., Blount, J. D., Nussey, D. H. \& Speakman, J. R. (2012). Oxidative damage, ageing, and life-history evolution: where now? Trends in Ecology \& Evolution, 27, 570-577. doi: 10.1016/j.tree.2012.06.006

Slos, S. \& Stoks, R. (2008). Predation risk induces stress proteins and reduces antioxidant defense. Functional Ecology, 22, 637-642. doi: 10.1111/j.1365-2435.2008.01424.x

Speakman, J. R., Blount, J. D., Bronikowski, A. M., Buffenstein, R., Isaksson, C., Kirkwood, T. B. L., Monaghan, P. ... (2015). Oxidative stress and life histories: unresolved issues and current needs. Ecology and Evolution, 5, 5745-5757. doi: 10.1002/ece3.1790

Stoks, R., De Block, M. \& McPeek, M. A. (2005). Alternative growth and energy storage responses to mortality threats in damselflies. Ecology Letters, 8, 1307-1316. doi: 10.1111/j.1461-0248.2005.00840.x 
704

705

706

707

708

709

710

711

712

713

714

715

716

717

718

719

720

721

722

723

726

Sunahara, T., Ishizaka, K. \& Mogi, M. (2002). Habitat size: a factor determining the opportunity for encounters between mosquito larvae and aquatic predators. Journal of Vector Ecology, 27, 8-20. doi:

Telang, A., Buck, N. A. \& Wheeler, D. E. (2002). Response of storage protein levels to dietary protein levels. Journal of Insect Physiology, 48, 1021-1029. doi: 10.1016/S0022-1910(02)00190-7

Telfer, W. H. \& Kunkel, J. G. (1991). The function and evolution of insect storage hexamers. Annual Review of Entomology, 36, 205-228. doi:

Travers, M., Clinchy, M., Zanette, L., Boonstra, R. \& Williams, T. D. (2010). Indirect predator effects on clutch size and the cost of egg production. Ecology Letters, 13, 980-988. doi: 10.1111/j.1461-0248.2010.01488.x

Trekels, H., Van de Meutter, F., Bervoets, L. \& Stoks, R. (2012). Species-specific responsiveness of four enzymes to endosulfan and predation risk questions their usefulness as general biomarkers. Ecotoxicology, 21, 268-279. doi: 10.1007/s10646011-0787-x

Uchida, K., Oda, T., Matsuoka, H., Moribayashi, A., Ohmori, D., Eshita, Y. \& Fukunaga, A. (2001). Induction of oogenesis in mosquitoes (Diptera: Culicidae) by infusion of the hemocoel with amino acids. Journal of Medical Entomology, 38, 572-575. doi: $10.1603 / 0022-2585-38.4 .572$

Van Dievel, M., Janssens, L. \& Stoks, R. (2016). Short- and long-term behavioural, physiological and stoichiometric responses to predation risk indicate chronic stress and compensatory mechanisms. Oecologia, 181, 347-357. doi: 10.1007/s00442-015$3440-1$ 


\section{9}

van Uitregt, V. O., Hurst, T. P. \& Wilson, R. S. (2012). Reduced size and starvation resistance in adult mosquitoes, Aedes notoscriptus, exposed to predation cues as larvae. Journal of Animal Ecology, 81, 108-115. doi: 10.1111/j.1365-2656.2011.01880.x

Yuval, B., Holliday-Hanson, M. L. \& Washing, R. K. (1994). Energy budget of swarming male mosquitoes. Ecological Entomology, 19, 74-78. doi: 10.1111/j.13652311.1994.tb00392.x

Yuval, B., Kaspi, R., Shloush, S. \& Warburg, M. S. (1998). Nutritional reserves regulate male participation in Mediterranean fruit fly leks. Ecological Entomology, 23, 211-215. doi: 10.1046/j.1365-2311.1998.00118.x

Zhou, G., Pennington, J. E. \& Wells, M. A. (2004). Utilization of pre-existing energy stores of female Aedes aegypti mosquitoes during the first gonotrophic cycle. Insect Biochemistry and Molecular Biology, 34, 919-925. doi: 10.1016/j.ibmb.2004.05.009 
Figure legends

742

743

744

745

746

747

748

749

750

751

752

753

754

755

756

757

758

759

760

761

762

763

764

765

Figure 1: Experimental work flow from larval predation exposure to adult collection for life history trait measurements and metabolite dosages.

Figure 2: Effect of larval predation threat on life history traits. a. Mean length of larval development; b. Mean female wing size; c. Mean adult weight; d. Mean number of produced eggs. The numbers in the bars indicate the number of mosquito samples. For the record, to avoid density effect, the number of larvae in control groups was adjusted according to the mean number of surviving larvae in predation settings. Consequently, sample size does not reflect control survivorship.

Figure 3: Effect of species and female size (wing size) on female egg load.

Figure 4: Carry-over effect of larval predation threat on adult longevity.

Figure 5: Carry-over effect of larval predation threat on metabolic content at emergence. a. Mean protein content; b. Mean lipid content; c. Mean carbohydrate content; d. Mean amino acid content. The numbers in the bars indicate the number of assays performed.

Figure 6: Carry-over effect of larval predation threat on adult oxidative status. a. Mean total anti-oxidant capacity expressed as Trolox equivalent; $\mathbf{b}$. Mean proportion of carbonyl (oxidized proteins) on total content of proteins. The numbers in the bars indicate the number of mosquito samples. 
An. coluzzii

An. gambiae

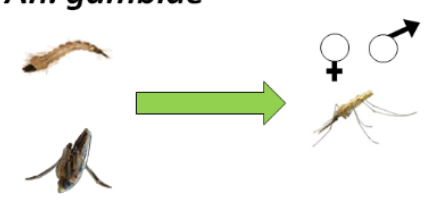

predator

Life history traits Development length Fecundity Survival Size and weight Oxidative stress Total antioxidant capacity Carbonyl Metabolic reserves Lipids Amino acids Proteins Carbohydrates

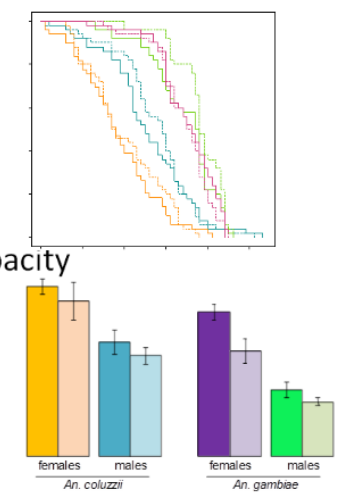

Highlights

- Life history traits and all the nutritional reserves were negatively affected 
An. coluzzii/ An. gambiae

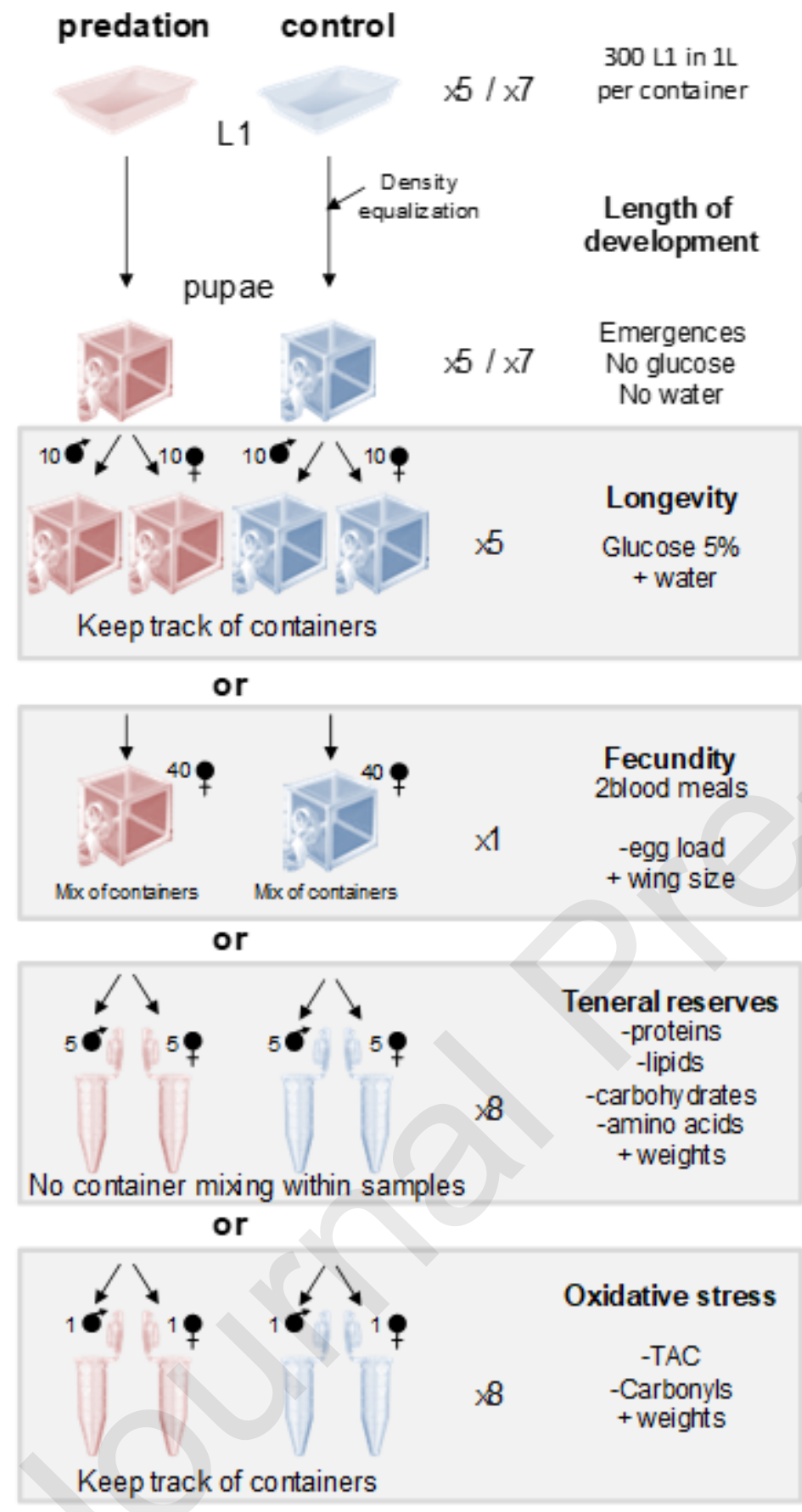


a.

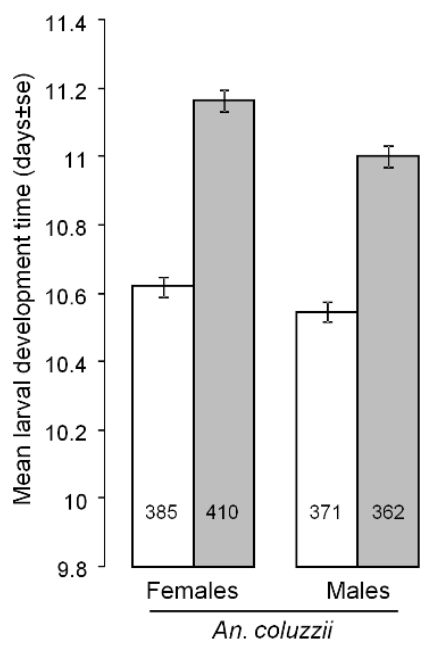

c.

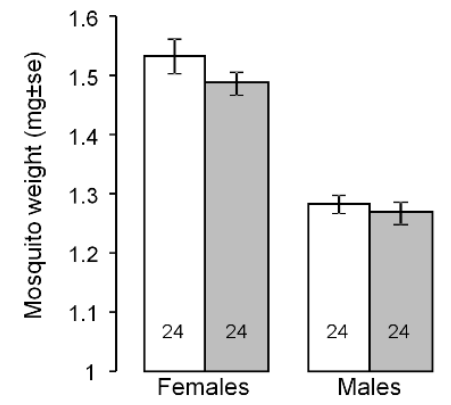

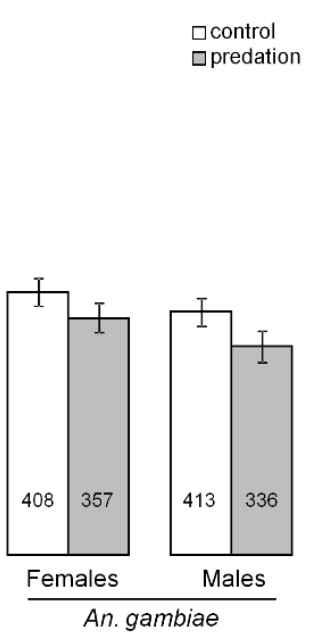

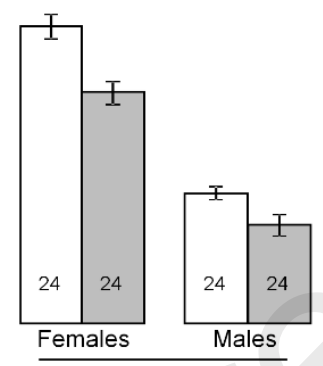

An. gambiae b.

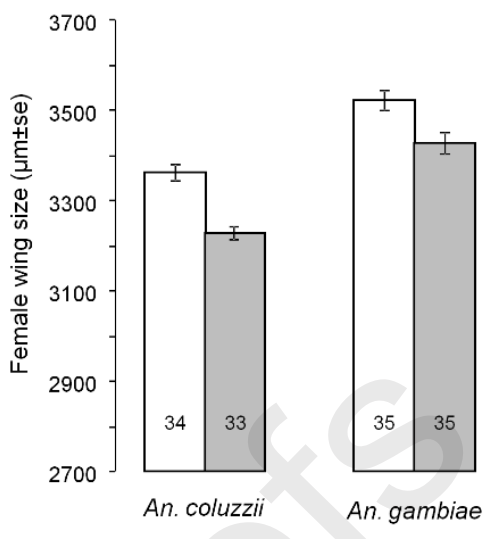

d.

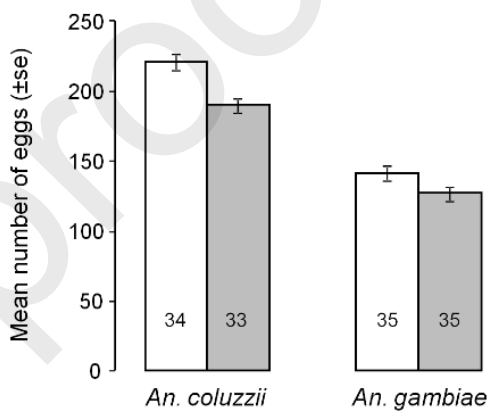




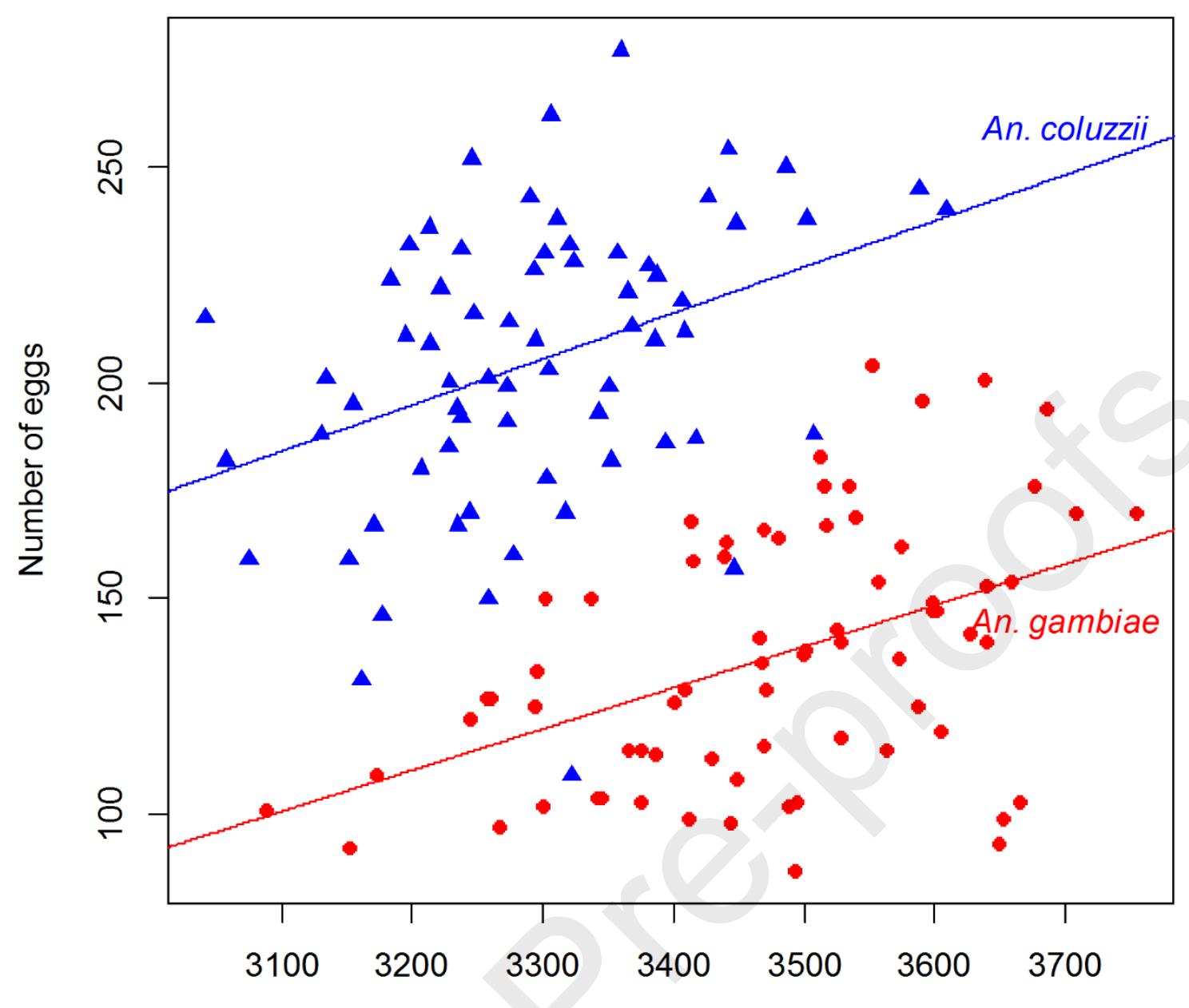

Wing length $(\mu \mathrm{m})$ 


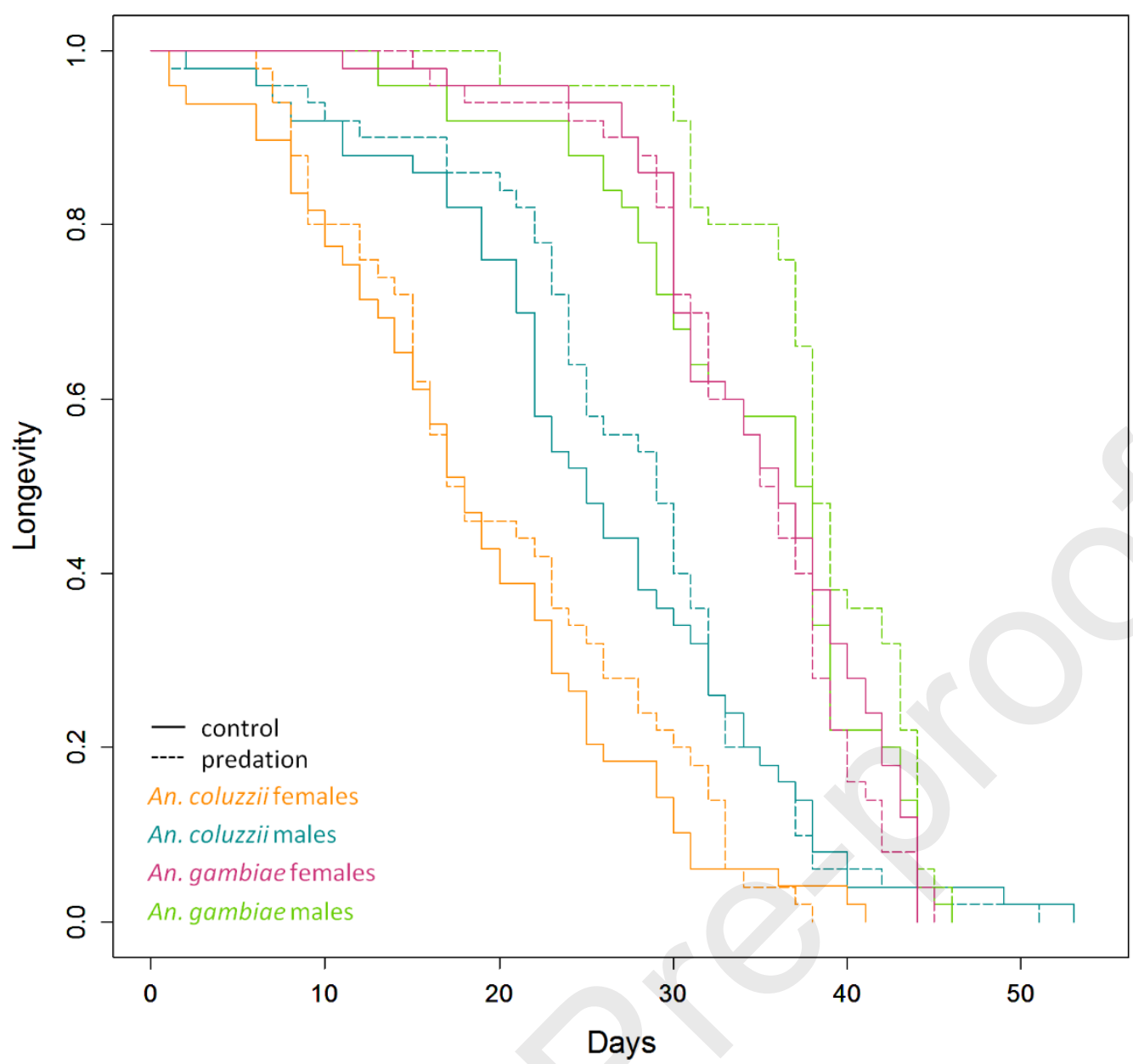

777

a.

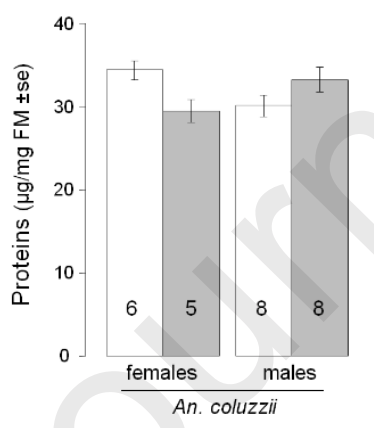

c.

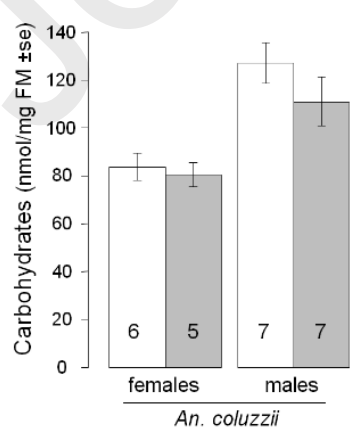

b.

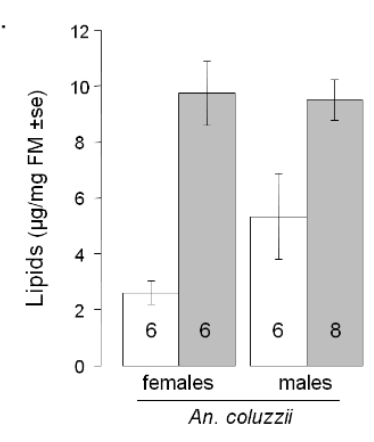

$\square$ control

$\square$ predation

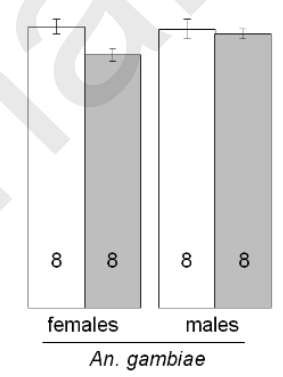

d.

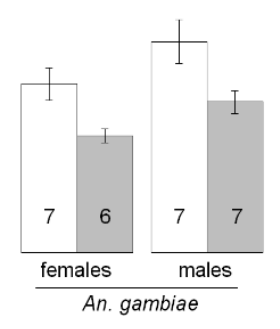

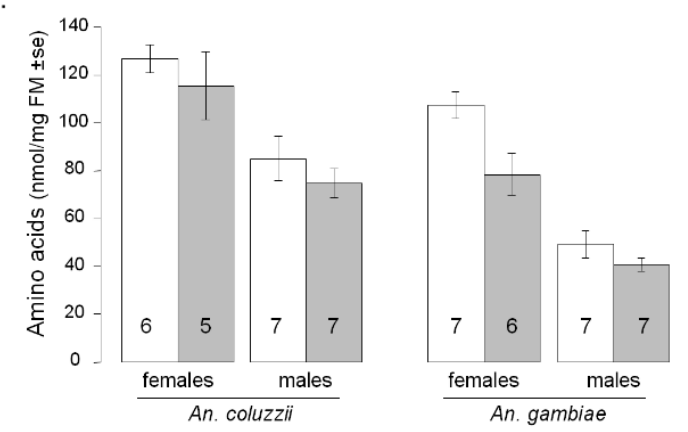


a.

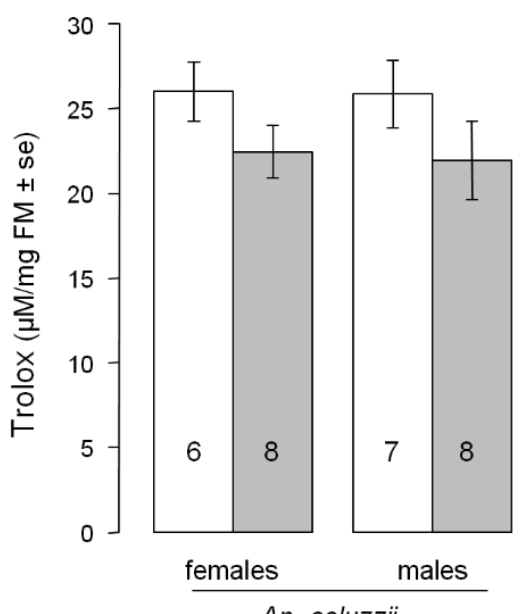

b. $\overline{\mathrm{o}}$

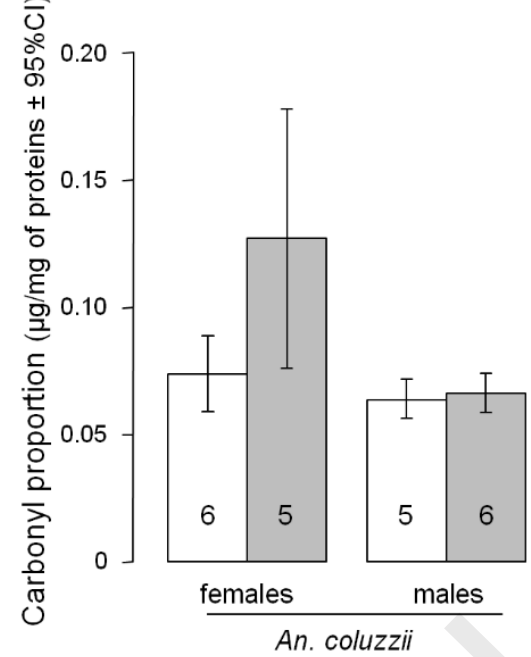

$\square$ control

$\square$ predation

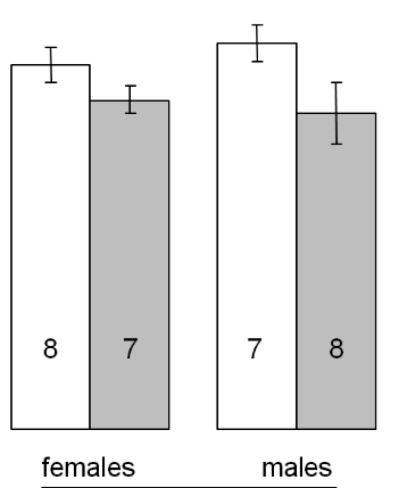

An. gambiae

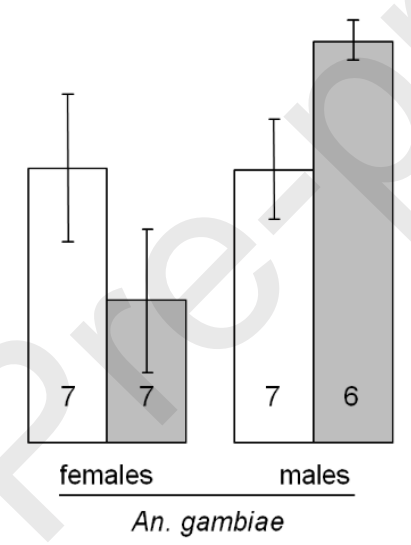

